\title{
La hermenéutica como lectura y traducción en George Steiner
}

\section{Hermeneutics as Reading and Translation in George Steiner}

\author{
Fernando Aurelio LóPEZ HERNÁNDEZ \\ Facultad de Filosofía y Letras \\ Universidad Nacional Autónoma de México
}

\begin{abstract}
Resumen
El artículo explora algunas tesis centrales de George Steiner —el acto de lectura, la traducción como interpretación y la razón de ser del arte- en el contexto de lo que él denomina el mundo de la "post-palabra". En efecto, en la sociedad contemporánea se ha erosionado la "cultura logocéntrica", aquella que tiene al logos como referencia sustantiva de la educación y de la formación intelectual. Para Steiner, el lector es un intérprete y éste debe ser, ante todo, un filólogo; el libro es una fuente inagotable de sentido y el quehacer hermenéutico un arduo trabajo intelectual. La instrumentalización de la lectura ha provocado que cada vez sea más arduo para el lector contemporáneo el encuentro con textos cuya dificultad supone aislamiento, silencio, meditación, y que demandan una respuesta, un compromiso responsable frente a lo leído.
\end{abstract}

Palabras clave: hermenéutica, lectura, traducción, interpretación, arte, cultura

\begin{abstract}
The paper explores some central theses of George Steiner - the act of reading, translation as interpretation, and the raison d'être of art-in the context of what he calls the "post-word" world. It is evident that in contemporary society the "logocentric culture" has been eroded - that is to say, we have lost the confidence in the $\log o s$ as a substantive reference for education and intellectual guidance. For Steiner the reader is an interpreter who must be a philologist; the book is an inexhaustible source of meaning, and the hermeneutical work is an arduous intellectual effort. Therefore, the instrumentalization of reading has provoked difficulties for the contemporary reader when he encounters texts that demand isolation, silence, meditation, and a responsible commitment to what has been read.
\end{abstract}

Keywords: hermeneutics, reading, translation, interpretation, art, culture 


\section{LA HERMENÉUTICA COMO LECTURA Y TRADUCCIÓN EN GEORGE STEINER}

En un breve pero elocuente ensayo escrito en 1978 y publicado en español en Pasión intacta (2001) como "El lector infrecuente", Steiner elabora una magnífica interpretación de un cuadro de Jean Baptiste Siméon Chardin, pintor académico francés que vivió entre 1699 y 1779. Su intención es mostrar a cabalidad el ethos del filósofo, del humanista, del escritor en Occidente - un modo de ser que ha tenido como centro de gravedad al libro- - El cuadro en cuestión muestra a un personaje en su estudio, vestido de gala, con sombrero, sentado a la mesa y concentrado ante un volumen de folios encuadernados a mano. Junto al texto se halla dispuesto su estilete y un reloj de arena; en el ambiente perdura el silencio, al tiempo que el texto y el lector se iluminan: Le philosophe lisant. Lo primero que destaca Steiner es la actitud de apertura respetuosa, cortés, cordial, del lector frente al libro: leer no es un pasatiempo, un mero acto de entretenimiento; implica, más bien, un verdadero encuentro, la posibilidad de entrar en contacto con una revelación. Por ello, la ocasión amerita un vestido y un decoro apropiados, con la cabeza cubierta, como se hace al ser partícipe de un rito sacramental: no se acude al oráculo vestido como todos los días. En el cuadro, Steiner subraya la presencia del reloj de arena, símbolo de una doble temporalidad: la pasajera, del lector; la perdurable, del texto. Leer es situarse en un continuo en el que la palabra permanece sustantiva: "Su lectura es un eslabón en la cadena de la continuidad performativa que suscribe [...] la supervivencia del texto leído" (Steiner, 2001: 22). Steiner también destaca, de entre los demás objetos que rodean al folio y al filósofo, a uno de ellos como primordial: la pluma. En efecto, el bien leer es siempre un acto que demanda una respuesta, la asunción de un compromiso: devolver la palabra con palabras.

Esa actitud de responsabilidad frente a lo leído explica la enorme riqueza que representa la presencia de los comentarios marginales o de las notas a pie de página - tanto en la literatura como en la filosofía - desde la Edad Media hasta nuestros días. Da cuenta, también, del devenir mismo de la hermenéutica y del desarrollo histórico de las letras en todas sus manifestaciones: "qui scribit, bis legit", reza la sentencia latina. "El intelectual es, sencillamente, un ser humano que cuando lee un libro tiene un lápiz en la mano" (Steiner, 2001: 29).

Recordemos, sin embargo, que las relaciones entre palabra y mundo, entre representación y realidad, entre signo y significado, han sido uno de los temas más prolíficos de la filosofía moderna y contemporánea. En este contexto se ubica el asunto capital de la hermenéutica: interpretar para comprender; comprender para dotar de sentido. Para Steiner el acto hermenéutico por excelencia es, sin duda alguna, la lectura y sus derivados, como la traducción. El lector es, fundamentalmente, un intérprete y debe asumir esa condición como un encuentro que no puede reducirse a la ejecución de una habilidad comunicativa: leer, sobre todo a los clásicos de la literatura, de la filosofía, no es un mero ejercicio de recepción o desciframiento de información. Cuando Steiner recuerda la experiencia infantil de su primer contacto con Homero (leerlo en griego y recitar un pasaje de memoria), afirma que: "Debía aprender a leer, a interiorizar la palabra y el comentario en la esperanza, por remota que fuese, de que un día tal vez sería capaz de proyectar sobre ese comentario, de añadir a la supervivencia del texto, 
un nuevo rayo de luz" (Steiner, 2000: 26). Aunque no todo texto se halla cargado con la misma riqueza significativa, con el mismo grado de polisemia, en efecto hay algunos cuyo carácter es tal que plantean un permanente y continuado desafío para la totalidad del lector: interrogan radicalmente sus facultades intelectivas y volitivas, así como sus respuestas emocionales. Hay otros, en cambio, para los que la interpretación es irrelevante, pues "el atributo que distingue lo trivial, la obra efímera, ya sea en la música, en la literatura o en las artes, consiste en que puede clasificarse y comprenderse de una vez por todas" (Steiner, 2000: 34). En contraste, hay ciertas obras cuya virtualidad semántica permite que las posibilidades de interpretación, comentario, crítica, análisis, revaloración y re-contextualización puedan ser inagotables.

Pero las obras con potencialidades significativas ilimitadas demandan el cumplimento de ciertas condiciones en los lectores y, por ello, el proceso interpretativo se plantea, en primer lugar, como un ejercicio de atención y cuidado por la letra: leerinterpretar supone una práctica filológica, pues sólo aquel que ama lo que lee puede llegar a comprenderlo. En segundo lugar, toda interpretación debe ser responsable, ha de dar respuesta al texto ya sea mediante la memorización o la réplica, o a través de la recreación o la traducción. En tercer lugar, es menester asumir que la lectura-interpretación conlleva la transformación de la inteligencia y la voluntad, pues, en efecto, la vida misma puede trastocarse sustancialmente:

La hermenéutica comparte frontera con la ética. Leer a Platón, a Pascal o a Tolstoi "a la manera clásica" es intentar una vida nueva y diferente. Es como postula Dante de un modo explícito, entrar en una vita nouva. En la mayor parte del arte y de la literatura esta convocatoria no es sistemática. Permanece implícita o representada en la forma. La obra de teatro, la novela, la naturaleza muerta de Cézanne complican tanto, se alejan tanto de la banalidad, aceleran tanto nuestro viaje interior (el motto spirituale de Dante) [...] que ya no somos los mismos. Los estratos, el paisaje de nuestras percepciones, han quedado modificados levísimamente o han sido re-alineados, sacudidos por un terremoto. (Steiner, 2000: 39-40)

Para Steiner, interpretar es traducir. Todo contacto con el lenguaje sugiere un ejercicio de traducción porque, según apunta — después de la pérdida de la lengua adánica, prístina, en la que palabra y mundo se fusionan en el acto mismo de enunciación creadora-, con el acontecimiento de Babel sobreviene una casi ilimitada proliferación de mundos, de modos distintos de vivir el acontecer temporal, de "mirar" y "decir" al ser. Pero también, el lenguaje es lo que hace posible la temporalidad humana: gracias a la gramática admitimos lo que ya no existe y lo que podría existir: la utopía y el advenimiento de lo improbable.

La evolución del habla humana — tal vez haya llegado tarde — hacia los subjuntivos, los optativos, los condicionales contrarios a los hechos y los futuros verbales [...] ha definido y salvaguardado nuestra humanidad. Gracias a ello podemos contar historias, ficticias o matemático-cosmológicas, acerca de un universo que se encuentra a billones 


\section{$56 \square$ LA HERMENÉUTICA COMO LECTURA Y TRADUCCIÓN EN GEORGE STEINER}

de años luz de nosotros; gracias a las cláusulas condicionales, al "si" [...], podemos, cuando nos place, negar, reconstruir, alterar el pasado, el presente y el futuro, cartografiar de otro modo los factores determinantes de la realidad pragmática, lograr que la existencia siga valiendo la pena. La esperanza es gramática. El misterio de la expresión del futuro o de la libertad — ambas se encuentran íntimamente emparentadas - es sintáctico. (Steiner, 2000: 113)

De ahí la relevancia radical del acto de traducción (interpretación). Se trata de una actividad del espíritu que sugiere un proceso dialéctico que pone en contacto dos mundos: uno de partida, otro de llegada. Ninguna traducción es unívoca, ello es imposible, pero no por eso los mundos son radicalmente inconmensurables. De entrada, el intérprete-traductor asume que el texto frente al cual trabaja tiene significado, que no está ante una conjunción azarosa de signos. Luego, ocurre una casi irremisible descomposición gramatical, como paso previo de la reconstrucción articuladora de sentido en la lengua (o el discurso) de llegada; y cuando el traductor es un auténtico filólogo y es responsable, puede en la traducción enriquecer su propia lengua, o bien hacer "decir más" al original actualizando sentidos y significados que se hallan en él de modo germinal, potencial. Esta labor, es decir, la pretensión de llevar hasta sus últimas consecuencias el radical deseo de conocer a través del texto, implica un enorme esfuerzo: la excelencia supone sacrificio, disciplina y entrega: "Tanto el pensamiento (conocimiento, Wissenschaft, e imaginación dotados de forma) como el amor, nos exigen demasiado. Nos humillan" (Steiner, 2000: 65).

Sin embargo, Steiner afirma que la cultura occidental vive en el momentum de la postpalabra, del cual es posible señalar algunos rasgos paradigmáticos: primero, el abuso en la política del discurso retórico para justificar no sólo dictaduras sino las más inhumanas atrocidades; segundo, la "desconfianza" en el lenguaje — suscitada primeramente por los poetas y luego por los filósofos: los analíticos y los distintos epígonos del estructuralismo - como vehículo para encontrar al ser, al mundo mismo; y, finalmente, la pauperización lingüística manifiesta en los medios masivos de comunicación y en los sistemas educativos contemporáneos en los que predomina la imagen sobre la palabra. "[E]s precisamente la imagen, en sus formas variables y reproducibles hasta el infinito, la que dominará la conciencia futura. Desde ahora, la lengua, sobre todo la que leen los jóvenes, se reduce al acompañamiento de las imágenes" (Steiner, 2007: 74).

A estos aspectos hay que sumar un elemento nuevo: las tecnologías de la información y la comunicación cuya ubicuidad es patente en prácticamente todos los terrenos de la cultura. Se trata, sin duda alguna, de una revolución sin precedentes cercanos, equiparable quizás, solamente, dice Steiner, a lo que significó la humana "manipulación del fuego":

La "técnica", tal como utilizaban el término Hegel y Heidegger, es un concepto insuficiente. En el mundo del ordenador, con su ritmo creciente de desarrollo y distribución — también en los hogares y en las escuelas primarias—, es un mundo en el cual 
unas constantes fundamentales como el conocimiento, la información, la comunicación, de hecho el control psicológico y social, incluso nuestra manera de entender el cerebro humano y el sistema nervioso (el "cableado") se están alterando y reevaluando radicalmente. (Steiner, 2008: 168)

En este contexto parece cierto que la emergencia del texto virtual trastocará definitivamente tanto el modo de preservar el conocimiento, como la simbólica manera de organizar el mundo propia de las bibliotecas desde Alejandría. Y modificará sustantivamente, también, al libro, al lector y a la lectura, lo cual es por demás significativo, porque como sostiene Steiner, la lectura de libros es una notable característica que distingue en Occidente al sabio o al amante del saber. En efecto, los hombres de letras, aquellos que han cultivado tanto la poesía como la metafísica — desde la antigüedad grecolatina y, por supuesto, en la tradición judeocristiana-, han tenido al libro como centro de referencia.

El "acto clásico de la lectura" [...] requiere de unas condiciones de silencio, de intimidad, de cultura literaria (alfabetismo) y de concentración. Faltando ellas, una lectura seria, una respuesta a los libros que sea también responsabilidad no es realista. Leer, en el verdadero sentido del término, una página de Kant, un poema de Leopardi, un capítulo de Proust, es tener acceso a los espacios de silencio, a las salvaguardias de la intimidad, a un determinado nivel de formación lingüística e histórica. (Steiner, 2007: 64)

Decir que lo que prima en el mundo que rodea a los lectores contemporáneos es lo opuesto resulta una perogrullada: ruido, "analfabetismo funcional", dispersión, distracción. Steiner señalaba con asombro, ya desde los años setenta del siglo pasado, que las prácticas de lectura habitual de los estudiantes promedio en los Estados Unidos iban acompañadas de música o de "ruido de fondo" proveniente del televisor. Hoy los distractores de la atención son múltiples y poliformes: la pantalla ofrece posibilidades ilimitadas de imágenes fijas o "animadas", de saltos cualitativos en los niveles de textualidad y, por supuesto, de interactividad. En contraste, insiste Steiner:

Desde la biblioteca de Alejandría hasta la celda de san Jerónimo, la torre de Montaigne o el despacho de Karl Marx en el British Museum, las artes de la concentración - lo que Malebranche definía como la "piedad natural del alma" — han tenido siempre una importancia esencial en la vida del libro. (Steiner, 2007: 65)

La multiplicación omnicomprensiva de los medios electrónicos obliga a plantear desde una nueva perspectiva el significado de lo que se quiere decir cuando se habla de "alfabetización" o "educación". Steiner afirma que, en Occidente, el hombre culto, el sabio, el estudioso, ha sido un "hombre de libros": saber leer y escribir (sobre todo en latín) distinguió a los monjes de los guerreros y del pueblo; luego, en la incipiente Modernidad, fueron ilustres personajes rodeados de bibliotecas privadas, como Montaigne 
o Erasmo, quienes han representado el culmen de dicha tradición. Posteriormente - $\mathrm{y}$ en buena medida gracias a la imprenta-, el liberalismo, la Ilustración y las evoluciones francesa e industrial procuraron una alfabetización para todos. No obstante, hasta ahora, la constante que define el alfabetismo ha sido el texto: manuscrito o impreso, laboriosamente configurado por amanuenses y copistas o bien reproducido mecánicamente por tipos móviles, recuperado en pergamino o en papel, el libro ha sido el centro de gravedad en el que confluye el pensamiento. "La revolución que ha dado lugar al ordenador moderno, a internet, a la red global, a la mercadotecnia planetaria de la información vía satélite [...] a la inteligencia artificial y a los medios, teóricamente ilimitados, de almacenamiento y recuperación de bancos de datos y mecanismos de búsqueda (Google), tiene un poder y una trascendencia incalculables" (Steiner, 2008: 168).

Las "incalculables consecuencias" a mediano y largo plazo no tienen que ver únicamente con lo más tangible y concreto - es decir, con el soporte mediante el cual se transmite o se "almacena" el conocimiento-, sino con el modo de percibir y concebir, de "construir" y "explicar" la realidad, de reconstruir y de proyectar la temporalidad, el acontecer. Sobre el "nuevo mundo digital", Steiner afirma: "[...] su contenido de información, su iconografía y su ámbito de referencias abarca todo constructo semiótico, toda aplicación lingüística ya sea en literatura, historia, el estudio de las bellas artes o la lógica formal. Indudablemente, esta omnipresencia tendrá con el paso del tiempo su 'retroalimentación', modelando pautas de pensamiento humano y hábitos de percepción" (Steiner, 2008: 169). Steiner sitúa lo que él llama el "inicio de la era libresca" en la plenitud del Renacimiento. Se trata, ni más ni menos, del momento de consolidación del libro como custodia del logos y del lector como su intérprete. Al parecer, hoy atestiguamos su ocaso: "La cultura de masas, la economía del espacio y el tiempo, la erosión de la privacidad, la supresión sistemática del silencio en las tecnologías del consumo, el desahucio de la memoria (del ejercicio de aprender de memoria) en el aprendizaje escolar, acarrean el eclipse del acto de la lectura, del libro mismo" (Steiner, 2001: 10).

Este descentramiento de lo textual y del libro ha tenido repercusiones evidentes en el quehacer del pensamiento y la creación en Occidente; recordemos que para Steiner habitamos en la época de la postpalabra, en la era del epílogo —es decir en un peculiar momento que surge con el abandono de la confianza en el logos, en la palabra y en la razón, como medios para dar cuenta del mundo- . Este tiempo crucial, según Steiner, surge con los poetas franceses Mallarmé y Rimbaud. El primero ha puesto en crisis la íntima relación entre palabra y mundo, pues para él lo que legitima al término "rosa" es, en efecto, "la ausencia de toda rosa". Dice Steiner: "La palabra rosa no tiene tallo, hoja, ni espina. Tampoco es color rosa, rojo o amarillo. No despide aroma alguno. Es, per se, una marca fonética totalmente arbitraria, un signo vacío" (Steiner, 1989: 125). Nos encontramos así ante la no correspondencia entre el decir y el ser; el lenguaje es un juego autorreferencial, vacío de contenidos. Pero la completa desarticulación la 
lleva a cabo Rimbaud cuando escribe Je est un autre': Steiner explica: "El deslizamiento es claro [...]. El ego ya no es él mismo. Para ser más precisos, ya no es él mismo para él mismo, ya no está disponible a la integración. Rimbaud deconstruye la primera persona del singular en todos los verbos, subvierte la domesticidad clásica del 'yo"" (Steiner, 1989: 130). La disgregación del sujeto y la inasible significatividad lingüística han puesto en severa crisis las aspiraciones de sentido y con ello no sólo quedan en entredicho el mundo de la teoría, sino también el de la poesis, puesto que ni hay autor, ni tampoco solidez ontológica en obra alguna. Así, afirma Steiner, el arte actual ha ido perdiendo gravedad reveladora de significado.

En contraste, Steiner sostiene que el arte es, esencialmente, conciencia de alteridad, de otredad, de encuentro, y como todo encuentro que tenga relevancia, se exige, de parte del intérprete, una dosis apreciable de cortesía. La obra, cuando pretende ser no sólo una estridencia en el mundo del espectáculo, es como un viajero que pide alojamiento; es un huésped cuya presencia nunca es trivial o efímera. Por ello, se impone una actitud de apertura cabal de la sensibilidad y el intelecto del receptor ante el innegable esfuerzo del artista, del autor, por recrear el ser: "Un gran poema, una novela clásica nos asedian; asaltan y ocupan las fortalezas de nuestra conciencia. Ejercen un extraño y contundente señorío sobre nuestra imaginación y nuestros deseos, sobre nuestras ambiciones y nuestros sueños más secretos" (Steiner, 2006: 26). Sin embargo, esta apertura no es fácil; requiere esfuerzo como todo trabajo filológico serio - esfuerzo que implica un ejercitarse con una cierta disciplina y disposición a las "gramáticas de la creación"; a la sintaxis del discurso artístico-. Esta búsqueda de acceso al sentido, esta praxis de elucidación hermenéutica, no puede ser trivial o un mero entretenimiento lúdico porque

En Occidente, es un hecho evidente el que los escritos, las obras de arte, las composiciones musicales que son referencia central comportan lo que es "grave y constante" (los epítetos son de Joyce) en el misterio de nuestra condición. [...] Hay una afirmación de D. H. Lawrence que lo resume todo: "Siempre siento como si estuviera des-

${ }^{1}$ Steiner se refiere a la cartas que Rimbaud escribió a Goerges Izambard y a Paul Demeny en mayo de 1871. Cito un fragmento de la primera: "Maintenant, je m'encrapule le plus possible. Pourquoi? Je veux être poète, et je travaille à me rendre Voyant: vous ne comprendrez pas du tout, et je ne saurais presque vous expliquer. Il s'agit d'arriver à l'inconnu par le dérèglement de tous les sens. Les souffrances sont énormes, mais il faut être fort, être né poète, et je me suis reconnu poète. Ce n'est pas du tout ma faute. C'est faux de dire: Je pense: on devrait dire: On me pense. - Pardon du jeu de mots. JE est un autre. Tant pis pour le bois qui se trouve violon, et Nargue aux inconscients, qui ergotent sur ce qu'ils ignorent tout à fait!" La versión de castellana de Juan Abeleira es la siguiente: "Por el momento, lo que hago es encrapularme todo lo posible. ¿Por qué? Quiero ser poeta, y me esfuerzo en volverme Vidente; yo apenas sabría explicárselo, y aunque supiese, usted no comprendería nada en absoluto. Se trata de alcanzar lo desconocido por medio del desarreglo de todos los sentidos. Los sufrimientos que ello conlleva son enormes, pero hay que ser fuerte, haber nacido poeta, y yo me he reconocido poeta. No es culpa mía en absoluto. Nos equivocamos al decir: Yo pienso; deberíamos decir: Alguien me piensa. Perdón por el juego de palabras. YO es otro. Tanto peor a la madera que se descubre violín, y jal carajo los inconscientes que pedantean acerca de lo que ignoran por completo.” (Rimbaud, 1933: 103) 
nudo, dispuesto a ser atravesado por el fuego de Dios todopoderoso; y es una sensación bastante horrible. Hay que ser terriblemente religioso para ser artista". Y tenemos a Yeats: "Ningún hombre puede crear como lo hicieron Shakespeare, Homero o Sófocles si no cree, con toda su sangre y su coraje, que el alma del hombre es inmortal". Y las citas podrían continuar. Bertrand Russell declaró con agudeza que Dios había dado al hombre demasiados pocos indicios de Su existencia para que la fe religiosa fuera plausible. Sin embargo, [...] esta observación no tiene buen oído. Excluye toda la esfera de lo poético, ya sea metafísico o estético; excluye la música y las artes, sin las cuales la vida del hombre podría no ser viable. (Steiner, 1989: 283, 287-288)

Se trata, sin duda alguna, de una propuesta que resulta por demás provocadora en un contexto en el que el encuentro directo con el arte sustantivo es cada vez más arduo. En un mundo parasitario, que se nutre no de la experiencia literaria directa, sino del resumen del resumen; en un mundo dónde se justifica la banal superficialidad propia de vacua grandilocuencia de un tiburón en una pecera de formol (Demien Hirst), aparece como imperativo ético recuperar las presencias reales que se insinúan tremendamente en la excedencia de sentido propias del "arte serio" (Steiner dixit). Perdernos de esa experiencia es lastimoso, menguante, empobrecedor, porque al final lo que va de por medio es que, a través de la vivencia estética, podemos atisbar de cierto modo las luces de lo eterno. Y eso no es cualquier cosa.

Para terminar, recuperemos dos elementos que son primordiales en esta fenomenología del "filosofar leyendo", del lector-traductor-intérprete-responsable propuesta por Steiner: memoria y silencio. En efecto:

El lector clásico [...] sitúa el texto que lee dentro de una multiplicidad resonante [la memoria]. El eco contesta al eco. La analogía es precisa y contigua, corregir y enmendar justifican un precedente recordado con exactitud. El lector replica al texto a partir de la articulada densidad de su propio acopio de referencias y recuerdos. La idea de que las musas de la memoria y de la invención son una sola es antigua y poderosa. (Steiner, 2001: 38)

Un lector inhábil en las artes de la memoria es, pues, un mal lector; leer sin recordar es, en realidad, no leer. De ahí, según Steiner, la preeminencia que le da el lector clásico a la retención de pasajes significativos de las Escrituras, de la lírica, de la épica, de las leyes. El recuerdo hace posible la conmemoración celebratoria de la comunidad, pero también la recreación en el corazón, en la intimidad de la conciencia, de la significatividad reveladora de las palabras y, con ello, la posibilidad de un pensar, un decir y un hacer responsables derivados de la lectura. Así, filosofar es leer y retener; aquel que aspira al saber no puede ser un desmemoriado.

El otro aspecto esencial en esta "praxis lectora" es el silencio: "El vigor de la memoria sólo puede sostenerse allí donde hay silencio. [...] Aprender de memoria, transcribir fielmente, leer de verdad significa estar en silencio y en el interior del silencio" (Steiner, 2001: 39). El silencio es condición de posibilidad de todo acto poiético, es 
circunstancia irremplazable que conduce al pensamiento profundo; es antesala de la contemplación:

[...] los dones y formas del silencio que tengo en mente son más reacios a la definición y mucho más a la cuantificación estadística. Son sobre todo internos. Perseveran y permiten los hábitos de concentración, de densa atención, de retirada de lo "impertinente" - con el doble significado de lo banal e inoportuno y de "lo que no es pertinente"- de los que son ejemplo el recogimiento total de los maestros de meditación o el de los maestros de ajedrez. Estas órdenes de cierre al exterior, de contradicción con lo mundano [...] Florecen en un cierto clima histórico y social. Proceden del ejercicio de la atención dirigida y de la memoria ordenada, un ejercicio que expresa los ideales de un medio dado, que se hace posible en la disponibilidad de un espacio de paz (la ermita, el estudio emblemático de san Jerónimo, el aislamiento invernal en que meditaba Descartes, los paseos nocturnos de Kierkegaard, o la cabaña forestal de Heidegger, fuera del alcance del mundo). En la historia occidental han existido épocas privilegiadas de silencio. Las técnicas filosóficas, la poética del siglo XVII, el enclaustramiento voluntario de Pascal o de Spinoza culminarán en la célebre equivalencia de Malebranche entre la atención, la concentración escrupulosa de la mente y la "piedad del alma". (Steiner, 2005: 318-319)

Por el contrario, es evidente que las tareas del filólogo, del hermeneuta, aquellas que tienen que ver con ejercicio cabal de las potencialidades creativas y discursivas del espíritu, se han visto asediadas y acrecentadas en la era digital por un cúmulo de distractores sin precedentes cuya irrupción invade e irrumpe las posibles pausas meditativas, los espacios de tensión creativa. Esta suerte de sinergia que, según Steiner, surge entre el silencio y la visión esclarecedora, se pierde, paradójicamente, en el multisensorial mundo digital que nos deja sordos, ciegos.

Tras el nacimiento de los medios de comunicación de masas en la época romántica hasta la ruptura de los diques con Internet y la Red planetaria, ya nadie puede calcular el volumen ni el ritmo de las novedades, de las informaciones, de las sugerencias verbalizadas o imaginadas que nos sumergen y solicitan nuestra atención, que sacuden las emociones y la memoria individuales. [...] El impacto sobre las antenas de la conciencia es incesante, el ruido dirigido al yo profundo, imparable. Busca y persigue ahora el ensordecimiento de lo subliminal. Las luces estroboscópicas de la inmediatez - ya sean los estímulos sensoriales de la información o de lo imaginario- nos ciegan los espacios de la visión. (Steiner, 2005: 317)

El silencio es, pues, una pausa, una espera y, por ello, un espacio de esperanza; es, también, condición de posibilidad del logos mismo, de la palabra, de la razón, del ser. No en vano Steiner evoca el "inefable silencio" que precedió al Big Bang, luego del cual es ineludible la presencia del "ruido de fondo". Palabra y silencio: dos caras de la misma moneda. 
Bibliografía

RimBAuD, Arthur. (2014). Iluminaciones, seguidas de Cartas del vidente (Juan Abeleira, Trad.) Madrid. Hiperion.

SteIneR, George. (1989). Presencias reales (Juan Gabriel López-Guix, Trad.). Barcelona: Destino.

SteINER, George. (2000). Errata (Catalina Martínez, Trad.). Madrid: Siruela.

STEINER, George. (2001). Pasión intacta (Menchu Gutiérrez y Encarna Castrejón, Trad.). Madrid: Siruela.

STEINER, George. (2005). Gramáticas de la creación (Andoni Alonso y Carmen galán, Trad.). Madrid: Siruela.

STEINER, George. (2006). Lenguaje y silencio (Miguel Ultorio, Trad.). Barcelona: Gedisa.

SteINER, George. (2007). Los logócratas (María Condor, Trad.). México: FCE.

SteIner, George. (2008). Los libros que nunca he escrito (María Condor, Trad.). México: FCE. 